\title{
CARACTERIZACIÓN DEL AGENTE NARRATIVO EN LAS EXPERIENCIAS VIVIDAS*
}

\author{
Fecha de entrega 20171006 \\ Fecha de evaluación 20171027 \\ Fecha de aprobación 20171126
}

\author{
Guillermo Freydell**
}

\section{Resumen}

La dimensión hermenéutica de las experiencias vividas se ha abordado desde una reducción analítica que suspende temporal y espacialmente la caracterización de agente narrativo. La racionalidad narrativa podría ofrecer una estructura dinámica en la configuración de la identidad del agente narrativo, además de posibilidades formativas que amplían sus dominios de significación y acción. El artículo de reflexión presenta elementos estructurales de la narrativa para caracterizar el agente narrativo. Esquematismo, tradición y triple mímesis, estructuran el texto como base para la configuración de historias que revelan la identidad característica del agente narrativo.

Palabras clave: narrativa, narrador, lector, mímesis e identidad.

* Este artículo de reflexión forma parte del desarrollo de la tesis doctoral, "Cuerpo vivido y procesos deliberativos bioéticos en espectadores del acoso escolar: una propuesta metodológica de intervención". Investigación inscrita al grupo Humanitas de la Universidad Militar Nueva Granada, Bogotá-Colombia. Citar como: Freydell, G. (2018). Caracterización del agente narrativo en las experiencias vividas. Cuadernos de Filosofia Latinoamericana, 39(118), 159-176. DOI: https://doi.org/10.15332/10.15332/ s0120-8462.2018.0118.09

** Ingeniero Mecánico Universidad Pontificia Bolivariana, Medellin-Colombia. Psicólogo Universidad Nacional Abierta y a Distancia UNAD, Bogotá-Colombia. Mgister en Ingeniería Industrial Universidad de los Andes, Bogotá-Colombia. Estudiante de doctorado en Bioética, Universidad Militar Nueva Granada, Bogotá-Colombia. Correo electrónico: gfreydell@gmail.com. ORCID: 0000-0001-5938-1205. 


\section{Abstract}

The hermeneutic dimension of the lived experiences has been approached from an analytical reduction that temporarily and spatially suspends the characterization of narrative agent. Narrative rationality could offer a dynamic structure in the configuration of the identity of the narrative agent, as well as formative possibilities that extend its domains of meaning and action. The article of reflection presents structural elements of the narrative to characterize the narrative agent. Schematism, tradition and triple mimesis, as a basis for the configuration of stories that reveal the characteristic identity of the narrative agent.

Keywords: Narrative, narrator, reader, mimesis and identity.

\section{Resumo}

A dimensão hermenêutica das experiências vividas se tem abordado desde uma redução analítica que suspende de forma temporal e espacial a caracterização de agente narrativo. A racionalidade narrativa poderia oferecer uma estrutura dinâmica na configuração da identidade do agente narrativo, além de possibilidades formativas que ampliam seus domínios de significação e ação. $\mathrm{O}$ artigo de reflexão apresenta elementos estruturais da narrativa para caracterizar o agente narrativo. Esquematismo, tradição e triple mimese, estruturam o texto como base para a configuração de histórias que revelam a identidade característica do agente narrativo.

Palavras-chave: narrativa, narrador, leitor, mimese e identidade.

\section{Introducción}

La pluralidad de posibilidades de significados de la historia de una vida requiere de interpretación, por consiguiente, de hermenéutica (van Manen, 1997). Domingo (2007) establece que el razonamiento puro y objetivo no es un camino válido

* Este artigo de reflexão forma parte do desenvolvimento da tese de doutorado "Corpo vivido e processos deliberativos bioéticos em espectadores do assédio escolar: uma proposta metodológica de intervenção". Pesquisa inscrita ao grupo Humanitas da Universidade Militar Nueva Granada, Bogotá - Colômbia. 
para dar cuenta de las experiencias vividas: se requiere de una razón narrativa o hermenéutica. Sin embargo, autores como Domingo, Bolívar y Passeggi, entre otros, no hacen distinción entre razón narrativa y razón hermenéutica, ya sea en la expresión o interpretación de las experiencias vividas. Se entiende que la narrativa implica hermenéutica, y hermenéutica implica narrativa:

a) Las narraciones forman parte de nuestra vida, somos narradores de nosotros mismos. [...] La narración es una forma de producir sentido. [...] Y allí donde hay sentido -que puede ser múltiple- puede haber ambigüedad, $y$, por tanto, hay hermenéutica. La hermenéutica se define como la interpretación del sentido, interpretación de la narración. [...] (Domingo, 2007, p. 28).

b) “Una hermenéutica-narrativa, [...], permite la comprensión de la complejidad psicológica de las narraciones que los individuos hacen de los conflictos y los dilemas en sus vidas" (Bolívar, 2002, p. 6).

c) "El narrador, redefiniéndose como aprendiz, se reinventa (formación). En este proceso hermenéutico de permanente interpretación y reinterpretación de los hechos, el adulto reelabora el proceso histórico de sus aprendizajes (acción)” (Passeggi, 2011, p. 35).

Existe una mutua implicación entre narrativa y hermenéutica, pero como procesos, podrían presentar diferencias: la narrativa es la expresión de la vida de quien narra (Domingo y Feito, 2013), y la hermenéutica es la interpretación de esta expresión (Mieles, Tonon y Alvarado, 2012; Domingo, 2005; van Manen, 1997). A pesar de que estas definiciones podrían conducir a procesos diferentes, los autores no establecen una distinción. Ricoeur tampoco hizo una diferenciación explícita entre narrativa y hermenéutica, ya que son conceptos recurrentes, pero en su obra sí estableció referentes de dos procesos diferentes: en Lo justo 2, aborda la hermenéutica como una ética aplicada (hermenéutica de la acción que gira entre la argumentación y la interpretación), y en Tiempo y narración, aborda la estructura narrativa de una experiencia vivida.

Generalmente la caracterización del sujeto en las experiencias vivida, se ha fundamentado desde la hermenéutica que utiliza el análisis temático o paradigmático para la interpretación de estas experiencias, reduciendo, a partir de categorías y códigos, la expresión del agente narrativo (Mieles, Tonon y Alvarado, 2012; van Manen, 1997). El agente narrativo es sujeto en la acción narrativa, es decir, discurre entre la acción del sujeto que narra y la acción del sujeto que lee o escucha. Sin 
embargo, en la reducción de este agente, desde la hermenéutica, se pierden aspectos importantes de la narrativa, como los procesos de construcción de identidad y de formación del agente narrativo: la reducción a categorías de análisis conduce a perderse el proceso de construcción de identidad y de formación que se da en el enlazamiento de todos los eventos vividos, en una trama temporal que posee estructura y significado. Esta estructura como un todo unificado en la trama temporal no es susceptible de ser reducida (Bolívar, 2002).

El relato, como manifestación viviente de la identidad narrativa de quien narra o lee, caracteriza al sujeto en el movimiento temporal y espacial de la trama, constituyéndose el sujeto como un proyecto abierto en la construcción de nuevos significados (Ricoeur, 1999). Toma relevancia determinar los elementos estructurales que se deben tener en cuenta en la caracterización y formación del sujeto narrador o lector (agente narrativo) en las experiencias vividas. Para lograr este fin, se partió del planteamiento que esquematismo, tradición y triple mímesis, sin ser elementos que se enlazan de forma lineal, se podrían encontrar para configurar en el acto narrativo, historias nacientes en las que se develaría la identidad característica del agente narrativo (narrador/lector) en la forma tradicional de verse a sí mismo, al otro y al mundo en las experiencias vividas. Y al mismo tiempo, este proceso dinámico de caracterización podría configurarse como un proceso de formación o refiguración que le permite al agente narrativo ampliar su dominio de significación y acción.

El desarrollo de este planteamiento estableció un camino en el que sobresalen cuatro momentos. En el primer momento, se muestra cómo el esquematismo de la función narrativa provee al sujeto la posibilidad innovadora de construir un relato a partir de lo establecido, a la vez que capacita al lector de la facultad para atribuir un significado a dicha historia (Tornero, 2008). En el segundo momento, se toma la narrativa como proceso de mímesis que aporta estructura a las historias nacientes. En el tercer momento, las historias nacientes son vistas como voces que buscan ser escuchadas, una identidad que puede ser configurada por el agente narrativo. En el cuarto momento, la identidad narrativa hace eco a la acción del sujeto, identidad que es puesta en escena por las experiencias de una vida narrada (Ricoeur, 1999). La identidad narrativa se configura en el acto narrativo como una tradición inteligible: lo permanente y lo innovador del agente narrativo que le permite abrazarse a sí mismo, al otro y al mudo de forma significativa.

Finalmente, estos cuatro momentos se reúnen para que, racionalidad narrativa, esquematismo de la función narrativa (o esquematismo), tradición, triple mímesis, 
historias nacientes e identidad narrativa, se encuentren para brindar una forma de pensar narrativa, la cual conduce a que la caracterización y la formación del agente narrativo (narrador/lector), emerjan en el mismo acto narrativo de sus experiencias vividas.

\section{Narrativa, esquematismo y tradición}

La temporalidad, como base de toda experiencia vivida, provee organización a la existencia, una organización que es puesta en escena gracias a símbolos lingüísticos que se articulan a través del acto narrativo, brindando inteligibilidad a la experiencia vivida. Dicho de otra manera, esta organización lingüística aporta sentido e inteligibilidad al relato, al tener como referencia lo temporal (Ricoeur, 1999). Ricoeur (2004) partió de la hipótesis que toda experiencia humana, la cual es organizada y esquematizada por la acción narrativa, comparte una característica común, lo temporal: todo lo que acaece en el tiempo se puede narrar, a la vez que todo lo que se vive y se narra se desenvuelve en el tiempo.

Una narración consta de tres momentos (Ricoeur, 2004): inicio, medio y fin, una organización de los acontecimientos en un relato histórico o de ficción, configurando una trama inteligible para el lector. El acontecimiento o situación debe aportar al progreso de una historia, y su comprensión se logra gracias a la inteligibilidad de la trama (Tornero, 2008; Cárdenas, 2012). Es decir, la capacidad configurativa del lector de desenvolver temporalmente la trama de una historia como algo significativo. Esta capacidad de desenvolvimiento hace referencia a la tradición: el aporte innovador en la construcción de la trama de una historia, la cual se basa en presupuestos normativos ya dados o sedimentarios. En la trama de una historia, se concatenan la sedimentación y la innovación, puesto que la historia narrada desde una tradición tiene un esquematismo que permite desenvolverla desde lo dado hacia nuevas formas de significación (Tornero, 2008): la tradición prefigura la historia hacia una configuración innovadora y ficticia abriendo las posibilidades formativas (Passeggi y Souza, 2010) y refigurativas (Ricoeur, 2004) en el agente narrativo.

Historia-ficción, es el resultado de la clausura temporal de la experiencia vivida del sujeto gracias al esquematismo de la función narrativa. El esquematismo conduce a la síntesis entre historia y ficción, en el entrecruce de la inteligibilidad y la intuición: lo tradicional enriquece lo innovador, y lo innovador enriquece lo tradicional. (Ricoeur, 2004, p. 27) 
El esquematismo de la función narrativa da al sujeto la capacidad innovadora de crear una historia a partir de lo conocido, a la vez que faculta al lector del potencial para comprender dicha historia (Tornero, 2008). Esta esquematización, une actuaciones, situaciones y agente en una tradición para darle forma a la trama y hacerla inteligible al lector (Contursi y Forero, 2000). Es en este proceso que el texto es prefigurado y configurado, y posteriormente en el acto de lectura, refigurado. La mímesis, como proceso de esquematización (Ricoeur, 2004; Contursi y Forero, 2000), provee la estructura característica del narrador. Es decir, en el proceso de mímesis es que se revela el esquematismo de la función narrativa, evidenciando en el relato del sujeto, su forma particular y característica de configurar la temporalidad en una trama que desenvuelve una historia a partir de lo dado hacia formas innovadoras y ficticias que conducen a la formación y refiguración del sujeto.

\section{Triple mímesis}

La mímesis no se da como imitación de una acción por parte del agente narrativo (narrador/lector), sino, como una metáfora de la vida, facilitando una nueva lectura o inteligibilidad narrativa. Por este motivo, Ricoeur (1991) hizo una distinción entre vida y vivido, al establecer que la vida tiene que ver con lo biológico, con el dato, y lo vivido tiene que ver con aquellas experiencias que involucran en la acción narrativa, sufrimiento, con su respectiva significación. La acción narrativa del sujeto es una acción dirigida u orientada por la significación, una intencionalidad significativa de la cual surge una responsabilidad consigo mismo y el otro (Theidon, 2006; Johansson; 2008; Feito, 2013). La mediación narrativa se establece como herramienta de formación para el conocimiento de sí mismo y el otro, (Cornejo y Rojas, 2008; Passeggi y Souza, 2010, Passeggi 2011), puesto que el sujeto solo puede acceder a su comprensión de forma indirecta, metafórica y ficticia a través de la narrativa (Ricoeur, 2006). Ricoeur (2006) y García (2006) consideraron que la comprensión se da en el entrecruce del mundo ficticio del lector y del mundo ficticio de lo narrado. En la forma particular en que el lector es lector de una historia o de su propia historia, es que transforma su identidad. La comprensión, como movimiento ficticio del individuo de ponerse en el lugar del otro (Ricoeur, 1999), el lector ante la presencia de la historia narrada por sí mismo u otro, le demanda consciencia de su forma de ver el mundo, configurando el relato que tiene al frente como una historia que puede ser parte de sí. En este sentido, la historia puede transgredir o confirmar lo dado, ampliando en el lector su dominio de significación y acción, estableciéndose un proceso de formación o refiguración. Es así como la historia 
vivida por el sujeto puede ser comprendida gracias a un mundo dado que facilita su configuración narrativa, y que, en su lectura, conduce a la refiguración del lector hacia nuevas formas de ser en el mundo. Este proceso Ricoeur lo denominó triple mímesis.

Contemporáneo a Ricoeur, Bruner consideró que el ser humano cuenta con la predisposición para ordenar la experiencia vivida desde lo narrativo, y se apoyó en la mímesis de Aristóteles, al igual que Ricoeur, para mostrar que la función narrativa busca la comprensión de aquello que se sale de la tradición cultural (Bruner, 2006). Sin embargo, la mirada de Bruner sobre la mímesis, difiere a la de Ricoeur, al buscar “interpretar la vida en acción” (Bruner, 2006, p. 58). Bruner en su teoría de la revolución cognitiva, que hace parte de la primera etapa de su carrera profesional, buscó que las acciones tengan un significado. Esta significación pasa por tres tipos de representaciones: enactivo, icónico y simbólico. Para darse la representación completa de una bicicleta, en el proceso de desarrollo del individuo, primero se debe montarla, segundo dibujarla y finalmente definirla simbólicamente con el lenguaje (Bruner, 1963). En contraste con la lectura que hizo Bruner del mímesis, Ricoeur la tomó como una metáfora de la vida, no copiándola, sino como forma de facilitar una nueva lectura o comprensión de esta (Ricoeur, 2004; Bruner 2006). Sin embargo, la segunda etapa de Bruner, la revolución cultural (Guilar, 2009), fue concordante con las ideas y la teoría de Ricoeur. Bruner en esta nueva etapa, profundizó en la racionalidad narrativa como una alternativa a la racionalidad positiva que estaba presente en su primera etapa profesional. Los aportes que realizó Bruner a la racionalidad narrativa complementó los aportes de Ricoeur, los cuales se han visto reflejados en el análisis de narrativas en la investigación (biográfico) narrativa (Bolívar, 2002; Cornejo y Rojas, 2008). Desde lo metodológico, en el sentido del ejercicio del acto narrativo, la triple mimesis como proceso, facilita ampliar los horizontes de acción a partir del mismo acto narrativo de las experiencias vividas.

Ricoeur (2004) estableció la triple mimesis a partir de los aportes de Aristóteles sobre la narrativa, la cual estaba conformada por tres tiempos de composición: prefiguración (mimesis I), configuración (mímesis II) y refiguración (mímesis III):

a) La mímesis I (prefiguración), está conformada por todos los antecedentes que reúnen un conocimiento y facilita la comprensión del mundo. Es decir, no se puede comprender algo si no existiera la posibilidad de configurar algo ya configurado (Ricoeur, 2004), algo dado o sedimentado. Esta posibilidad de configurar algo, son todos los presupuestos que posee la persona para darle forma al mundo y atribuirles un sentido o significado a las experiencias vividas. Sin estos presupuestos no hay 
significado, y no podría conformarse la composición narrativa y, por tanto, una tradición.

b) La mímesis II (configuración), es el proceso de construcción de la composición narrativa de una situación determinada, es decir, con temporalidad y espacialidad. Ricoeur (2004) llamó a este proceso esquematismo de la función narrativa. Esta narrativa configura la tradición al contar una historia individual, una historia vivida que da forma a las experiencias en una historia con un orden que articula los diferentes eventos heterogéneos vividos cronológicamente para su comprensión como un todo. La historia puede ser retomada en cualquier momento, no solo en un momento cronológico interno del relato, sino también en cualquier momento diferente al momento en que se realizó el relato para su comprensión por el lector. En este punto, la narración biográfica construye un personaje que es concordantedisonante con la experiencia vivida del narrador: surge la identidad narrativa de quien narra. La concordancia-disonancia entre los relatos culturales y la identidad narrativa, lleva a que constantemente esta última, en su reinterpretación ante una tradición, se transforme. Estas historias, que son propulsadas por el cuerpo del narrador que abraza significativamente el mundo, son historias moldeadas por el proceso de esquematización (Ricoeur, 2004). Es un proceso recurrente, es decir, si hay significación, es porque hay esquematización, y si hay esquematización, es porque hay significación.

c) El lector cuando se enfrenta a un relato o historia narrada, este también se configura en el relato. Todo lector tiene presupuestos lingüísticos, semánticos, sintácticos y culturales que le permiten dar forma inteligible y significativa al relato que tiene al frente, de lo contrario, no se podría concretar la refiguración, el poder de formación del lector (mímesis III).

d) La mímesis III (refiguración), marca el encuentro entre dos mundos, el mundo configurado del narrador y el mundo configurado del lector (Ricoeur, 2004; 2006). En este encuentro, el lector incorpora el relato llevándolo a construir, a partir de la innovación, nuevos significados y, por consiguiente, nuevas posibilidades de acción. El lector en el momento de leer posee una capacidad de prefiguración y configuración aportadas por esquematismo de la función narrativa, que le permite reconocer el texto dentro de una tradición. Pero en este proceso de reconocer el texto, este brinda nuevos significados que lo conduce a actualizar su condición configuradora del texto, formando y transformando su visión tradicional de verse 
a sí mismo, al otro y al mundo. El esquematismo de la función narrativa esta tanto en la mimesis I, mimesis II, como en la mímesis III.

En la triple mímesis, los relatos son narrados por alguien para alguien, y en el proceso de configuración del relato, se está plasmando en él la forma de ver, valorar y asumir la vida. Por otro lado, el lector en su capacidad de configurar el texto a partir de su forma de ver, valorar y asumir la vida, en la lectura del texto se dan movimientos de formación y refiguración que llevan a actualizarlo a nuevos estados de ver, valorar y asumir la vida. Desde una experiencia de vida particular, concreta y narrada, se puede entrar en una identificación empática en la lectura del otro, estableciendo significados que pueden guiar las relaciones colectivas (Feito, 2013). Emerge la racionalidad narrativa como proceso que orienta la comprensión del agente narrativo de sí mismo y del otro en las experiencias vividas (Ricoeur, 1996).

Sin embargo, existen historias aún no narradas, experiencias no comprendidas y sin esquema, historias reprimidas por el sujeto y que pueden estar afectando la comprensión de sí mismo y del otro. Esto lleva a que la moral cimentada en la responsabilidad con el otro en la narrativa intersubjetiva, y la ética que se consagra en la refiguración de la acción narrada, se vean afectadas. La racionalidad narrativa, como un proceso de mímesis en la narrativa de las sensaciones, sentimientos y acontecimientos del sujeto, puede ayudar a propulsar estas historias nacientes y esquematizarlas en una narrativa biográfica del agente como texto significativo (Armstrong, 2007) para la constitución de su identidad.

\section{Configuración de una historia naciente}

Tanto para McEwan (1997) como para Ricoeur (2006), una vida se puede caracterizar a partir de las narrativas vividas e históricas del individuo desde el inicio de su vida hasta su fin. Puesto que una vida no se puede acceder sin la mediación de lo narrativo. Esta mediación, que conduce a la ficción, aporta carácter a lo narrado. La narrativa, se erige como recurso para dar cuenta de una vida vivida, caracterizarla y reflexionar sobre ella: Sócrates en Apología, establece que una vida que no es sometida a la examinación es una vida que no merece ser vivida.

La historia es una trama que concatena diferentes acontecimientos, de tal forma que sea inteligible, tanto para quien narra, como para quien lee. Si bien no se puede acceder directamente a la vida, el recurso narrativo implica una síntesis de todos los 
acontecimientos vividos que involucra situaciones, personas, acciones, relaciones, fortuna, infortunio, lo esperado y lo trágico. Una historia sintetiza temporalmente todos estos elementos en una concordancia-disonancia, surgiendo la historia como una totalidad, en la que se logra configurar la sucesión de eventos: cerrar o clausurar la historia como unidad inteligible. Esta clausura como unidad estructural del relato, permite volver hacia este y reflexionar sobre la fortuna y el infortunio, y su relación con las acciones del agente narrativo (narrador/lector), vinculando virtud y acciones que llevan a la felicidad. Ricoeur (2006) llamó a este proceso, Phronesis o inteligencia prudente.

Por otro lado, esta clausura estructural del relato, manifiesta un esquematismo que hace referencia a la tradición que intrinca la innovación y la sedimentación, es decir, lo cambiante (ipse) con lo permanente (idem) respectivamente. En palabras de Ricoeur (2006): “las normas cambian bajo la presión de la innovación” (p. 14). El juego entre estos dos elementos de la tradición en la temporalidad es que se configura en el personaje narrado sus características: la identidad narrativa del narrador. Sin embargo, la configuración no termina en el relato, se requiere del lector para la refiguración de lo vivo y de la experiencia vivida puesta en el relato: "en la intersección del mundo del texto con el mundo del lector" (Ricoeur, 2006, p. 15) es que se elabora significado, una síntesis de lo heterogéneo. Esta significación puede darse entre hombre-mundo (referencia), hombre-hombre (comunicación) o entre hombre-sí mismo (comprensión) (Ricoeur, 2006). Es en este sentido, que el lector ingresa al mundo de la ficción, al configurar su experiencia vivida con su imaginación, creando nuevos significados y ampliando su dominio de acción.

Ricoeur (2006) hizo referencia a tres elementos que contribuyen a la clausura del relato en una inteligibilidad narrativa de la experiencia vivida: semántica de la acción, mediatización simbólica y cualidad prenarrativa de la experiencia humana. La semántica de la acción lleva a que una acción sea familiar en la medida en que las historias articulan estas acciones como familiares. La mediatización simbólica lleva a que una acción puede ser articulada en una historia, gracias a la ilación de signos culturales. Y la cualidad prenarrativa de la experiencia humana hace referencia a las historias en estado naciente, es decir, a pesar de que toda historia hace referencia al drama de las acciones que gozan de temporalidad, existen historias que exigen ser narradas, acciones que, al ser reprimidas temporalmente por el inconsciente, no hacen eco al sufrimiento actual y que, a pesar de no poder mediatizarla por los símbolos 
culturales, hacen parte de la identidad del individuo. Estas son historias que aún no gozan de clausura estructural que lleven a una narrativa inteligible. Se requiere que estas historias emerjan a la superficie temporal como una voz que enlaza lo dado y lo sedimentario (mímesis I), con acción y sufrimiento en la configuración o producción innovadora de nuevos modos de significación (mímesis II): la historia goza de una clausura estructural de significado en toda su trama temporal.

Ricoeur (2006) hizo énfasis en la práctica psicoanalítica como estrategia para que emerjan del inconsciente los acontecimientos primitivos y reprimidos que, por el conflicto, no gozaron de clausura temporal, y así poder configurar una inteligibilidad narrativa. Historias reprimidas hacia historias efectivas en el individuo, las cuales aportan a la configuración de su identidad (Gomes de Oliviera, 2012): surge la identidad narrativa a partir de la composición de las historias nacientes.

\section{Identidad narrativa}

Feito (2013) considera que las narrativas comparten algo que se puede generalizar a partir de lo singular. El sujeto que narra impregna su identidad en el relato, y el sujeto que lee o escucha el relato, se puede identificar con el personaje narrado en costumbres y valores: "La historia de una vida se convierte en una historia contada" (Ricoeur, 1999, p. 342). Una historia contada por alguien para alguien. Estas historias manifiestan tanto el aspecto duradero como mutable del sujeto, aspectos que son puestos en un personaje ante situaciones que le han sido significativas. En este sentido, el sujeto al crear el personaje se está reinventando a sí mismo (ficción) en un proceso en el que mantiene en toda la historia su identidad. Esta identidad está dada por "la síntesis de lo heterogéneo" (Ricoeur, 1999, p. 347): la articulación y cierre adecuado de lo permanente (idem) con lo cambiante (ipse). Es en el mismo proceso creativo de elaboración de la trama, en que la historia narrada adquiere su identidad. La identidad narrativa de la cual goza el personaje tiene que ver con la forma única en que el sujeto establece su propio relato o historia (Martínez, 1999). Se manifiesta de forma directa aquellas formas de ver objetivas (idem) que, sin la mediatización narrativa, no podría poner en escena las formas de ver indirectas o subjetivas (ipse) en un inicio, en un intermedio y en un fin. La configuración del relato debe tener una clausura estructural y de significado, una síntesis de lo heterogéneo (Ricoeur, 1999). 
La identidad narrativa responde a la acción característica del sujeto, la cual es soportada por las experiencias de una vida narrada (Zapata, 2009; Guitart, Nadal y Vila, 2010). Esta experiencia de vida narrada no solo responde a la permanencia del sujeto (idem) responsable de una acción situada (con temporalidad y espacialidad), sino también a sus posibles cambios (ipse) que se dan en la refiguración por el paso del tiempo respecto a dicha acción (Martínez, 1999; Tornero, 2008; Zapata, 2009). Gracias a que esta dualidad es disuelta por la narración, el sujeto permanece en el tiempo y espacio a pesar de sus transformaciones (Ricoeur, 1999). Es así como la identidad narrativa del sujeto manifiesta características inmutables (idem) y características mutables (ipse), un sujeto reconocible en el tiempo a pesar de sus constantes transformaciones: una forma de caracterizar el agente narrativo (narrador/lector). La identidad narrativa se configura (mímesis II) como una inteligibilidad narrativa a partir de lo permanente o prefigurado en el agente narrativo (mímesis I), y que conduce a este hacia una mutabilidad o refiguración al hacer una lectura de sí mismo o del otro (mímesis III) en el mundo.

La identidad narrativa es uno de los aspectos que en el análisis de los relatos se busca identificar. La caracterización del sujeto, como forma de verse a sí, el otro y el mundo, es punto de referencia para los procesos de intervención. Esto se debe a que la caracterización permite contrastar un estado previo respecto a los cambios a que tiene lugar el agente narrativo (narrador/lector) a través de la intervención narrativa. Los principales métodos que abordan la caracterización del sujeto en las experiencias vividas se han erigido desde una racionalidad hermenéutica y desde el análisis paradigmático de las historias vividas. Sin embargo, la racionalidad narrativa, desde los aportes de Ricoeur, podrían aportar una forma de pensar que sobrepasa la racionalidad interpretativa de la hermenéutica en el análisis y caracterización de las experiencias vividas, hacia formas de pensar descriptivas, deliberativas y narrativas. "Para comprender algo humano, personal o colectivo, es preciso contar una historia" (Ortega y Gasset, 2001, p. 91).

\section{Caracterización del agente narrativo en las experiencias vividas}

Las diferentes historias, que son únicas respecto al significado que le asignan sus narradores, pueden contribuir a significados analógicos. La analogía no reduce una historia respecto otra, sino que permite realizar una síntesis de lo heterogéneo (Ricoeur, 
1999). Es decir, entre tramas de diferentes historias existe esquema o similitud, pero no igualdad, haciendo de la comprensión analógica una forma para identificar de la tradición narrativa del individuo, lo sedimentario y lo innovador, para así caracterizar su identidad narrativa a partir las experiencias vividas. El esquematismo de la función narrativa soporta la síntesis de lo heterogéneo que, en este caso, Ricoeur (1999) lo vio como una articulación de los diferentes elementos que constituyen la experiencia vivida que llevan a la formulación de unas premisas, y que son afectadas en cada experiencia nueva. Estas premisas cuando son concordantes y reconocibles en el tiempo, van formando un parámetro en el individuo, y gracias a la función narrativa, se establece la identidad narrativa. Esta concordancia de premisas en el tiempo es lo que Ricoeur (1999) llamó sedimentación.

La sedimentación, tanto en Merleau-Ponty (1994) como en Ricoeur (1999), es un aspecto consciente de que el sujeto puede invocar de sí y del otro. La sedimentación permite establecer una forma de ser en el tiempo como referencia para asignar un sentido, y el cual constantemente se está actualizando gracias a la innovación. Esto quiere decir que, para caracterizar el agente narrativo (narrador/lector), se podría recurrir a la tradición como esquema que articula sedimentación e innovación en el acto narrativo de las experiencias vividas del agente narrativo, revelando su identidad. La sedimentación da cuenta de las dimensiones de la personalidad del sujeto que permite hacer un esbozo fugaz de su identidad, a partir de sus experiencias vividas. Esto se debe, a que una vez se da cuenta el sujeto de esta sedimentación, y la pone en escena a través de la innovación en el acto narrativo, inmediatamente esta queda actualizada, abriendo nuevas significaciones del mundo (innovación), no pudiéndose atrapar objetivamente al sujeto (Merleau-Ponty, 1994). Por tanto, la tradición puede mostrar una tendencia a los cambios (ipse) como hábitos (idem), los cuales constantemente se están actualizando (Ricoeur, 1999).

La tradición, como esquema que articula lo sedimentario con lo innovador en la constitución de la identidad narrativa, se erige como base para la caracterización del agente narrativo en el acto narrativo de sus experiencias vividas. El esquema de la tradición es un proceso de prefiguración, configuración y refiguración que da estructura al acto narrativo de las historias nacientes: el acto narrativo, al ostentar de tradición, esquema y triple mímesis, provee de estructura a la historia de una experiencia vivida, dando como resultado una historia naciente, la cual revela la identidad narrativa que caracteriza al agente narrativo. Sin embargo, esta identidad 
al ser fugaz, gracias al proceso de actualización que provee el esquema de la tradición y la triple mímesis, el agente narrativo se establece como un proyecto abierto para futuras significaciones.

\section{Conclusiones}

La narrativa implica un doble movimiento: el desarrollo de un texto, el cual es leído por otro, un doble movimiento en el que narrador y lector se encuentran para la comprensión. Esto conduce a que el texto requiere de interpretación o hermenéutica. Visto de otro modo, si se habla de hermenéutica, es porque se hace referencia a un texto, a un relato, a una construcción narrativa para su interpretación.

Sin embargo, narrativa y hermenéutica como procesos, denotan diferencias a la hora de abordar la existencia del hombre. La hermenéutica es el proceso de interpretación de una narrativa, y la narrativa es el proceso de expresar o configurar una experiencia de vida, la cual tiene significado para el narrador o lector. La racionalidad narrativa se erige como forma de expresión de la experiencia vivida del agente narrativo (narrador/lector).

Una experiencia vivida puesta en escena, como resultado de un proceso de composición narrativa, es inteligible gracias al esquema que proporciona la tradición. El esquematismo de la función narrativa configura la tradición en la interacción entre sedimentación o prefiguración y la innovación o refiguración: la triple mímesis que da forma a una historia naciente portadora de identidad narrativa, y que caracteriza al sujeto narrador y lector (agente narrativo) en su experiencia vivida.

Los elementos que constituyen la caracterización del agente narrativo (narrador/ lector), no son elementos de un proceso lineal. El acto narrativo se manifiesta como proceso recursivo o circular en el que tradición, esquematismo y triple mímesis, no se pueden ubicar en una causalidad, son elementos emergentes en el mismo acto narrativo. Por tanto, si se toma el acto narrativo en el que se encuentran tradición, esquema y triple mímesis, da como resultado una historia naciente de experiencias vividas, la cual revela la identidad narrativa que caracteriza al agente narrativo.

Sin embargo, el agente narrativo (narrador/lector) es inacabable, no es una estructura cerrada sobre la cual se pueda atrapar con una caracterización como fin. La 
caracterización como acto narrativo de la experiencia vivida, permite identificar la tendencia a los cambios a partir de lo permanente en el agente narrativo. Una forma de plasmar su proceso de formación en una permanente actualización ante la vida como historia, a la cual se puede volver para reescribir: una forma de ser que cambia a partir de lo permanente, y lo permanente cambia a partir de las nuevas formas de ser en el mundo.

\section{Referencias}

Ahlzén, R. (2011). Illness as unhomelike being-in-the-world? Phenomenology and medical practice. Medicine, Health Care and Philosophy, 14(3), 323-331.

Armstrong, K. (2007). Epistemological hermeneutics in clinical praxis: Appropriating Paul Ricoeur. The University of Iowa.

Austin, J. (1962). Cómo hacer cosas con palabras. Barcelona, España: Paidos.

Bolívar, A. (2002). ¿De nobis ipsis silemus?: Epistemología de la investigación biográfico-narrativa en educación. Revista electrónica de investigación educativa, 4(1), 1-26.

Bruner, J. (1963). El proceso de la educación. México: UTEHA.

Bruner, J. (1985). Actual minds, posible worlds. Cambridge: Harvard University Press.

Bruner, J. (1997). La educación, puerta de la cultura. Madrid, España: Visor.

Bruner, J. (2006). Culture, mind, and narrative. London, New York: Routledge.

Cárdenas, L. (2012). El giro del tiempo al espacio: a propósito de Ricoeur. Acta fenomenológica latinoamericana, 4, 445-455.

Contursi, M., y Ferro, F. (2000). La narración: usos y teorías. Editorial Norma.

Cornejo, M., Mendoza, F., y Rojas, R. (2008). La investigación con relatos de vida: pistas y opciones del diseño metodológico. Psykhe (Santiago), 17(1), 29-39.

Crossley, M. (2003). Formulating narrative psychology: The limitations of contemporary social constructionism. Narrative inquiry, 2(13), 287-300.

Domingo, T. (2005). Hermenéutica y sabiduría práctica. Investigaciones fenomenológicas, 4, 131-146. 
Domingo, T. (2007). Bioética y hermenéutica: la aportación de Paul Ricoeur a la bioética. Veritas: revista de filosofía y teología, (17), 281-312.

Domingo, T., y Feito, L. (2013). Bioética narrativa. Madrid, España: Escolar y Mayo.

Feito, L. (2013). Bioética narrativa. Bulletí del Comitè de Bioètica de Catalunya, 9, 1-7.

García, J. (2006). La historia de una vida: un relato interpretante-interpretado en la construcción de conocimiento. Revista de filosofía Universidad de Costa Rica, 44(111-112), 43-48.

Gomes de Oliveira, R. (2012). La triple mimesis en la narrativa transmedia de la performance Esfuerzo. Revista Comunicación, 10(1), 115-130.

Goodley, D. (2001). Learning difficulties, the social model of disability and impairment: challenging epistemologies. Disability \& Society, 2(16), 207-231.

Guilar, M. (2009). Las ideas de Bruner: "de la revolución cognitiva" a la "revolución cultural". Educere, 13, 235-241.

Guitart, M., Nadal, J., y Vila, I. (2010). La construcción narrativa de la identidad en un contexto educativo intercultural. Límite, 5(21), 77-94.

Johansson, E. (2008). Empathy or Intersubjectivity? Understanding the Origins of Morality in Young Children. Studies in Philosophy and Education, 27(1), 33.

Mainetti, J. (2008). El complejo bioético: pigmalión, narciso y knock. Revista Latinoamericana de Bioética, 8(2), 30-37.

Martínez, A. (1999). Vida y literatura. Identidad personal e identidad del personaje. Thémata, 23, 271-276.

McEwan, H. (1997). The functions of narrative and research on teaching. Teaching and Teacher Education, 13(1), 85-92.

Merleau, M. (2000). Fenomenología de la percepción. Barcelona: Altaya.

Mieles, M., Tonón, G., y Alvarado, S. (2012). Investigación cualitativa: el análisis temático para el tratamiento de la información desde el enfoque de la fenomenología social. Universitas Humanística, 74, 195-225.

Ortega y Gasset, J. (2001). Historia como sistema. España: Biblioteca Nueva 5. ${ }^{a}$ edición. 
Passeggi, M., y de Souza, E. (2010). Memoria docente, investigación y formación. Buenos Aires, Argentina: Facultad de Filosofía y Letras.

Passeggi, M. (2011). Aproximaciones teóricas a las perspectivas de la investigación (auto) biográfica en educación. Revista Educación y Pedagogía, 23(61), 25.

Polkinghorne, D. (1995). Narrative configuration in qualitative analysis. International journal of qualitative studies in education, 8(1), 5-23.

Rendón, P. A. (2014). Hacia una semiótica del arte Implicaciones del pensamiento peirceano en el estudio del arte contemporáneo. Cuadernos de Filosofía Latinoamericana, 35(111), 127-145.

Ricoeur, P. (1991). From text the action: essays in hermeneutics II. Evanston: Northwestern University Press.

Ricoeur, P. (1996). Sí mismo como otro. Siglo XXI Editores.

Ricoeur, P. (1999). Historia y narratividad. Barcelona: Paidós.

Ricoeur, P. (2004). Tiempo y narración I. Siglo XXI Editores.

Ricoeur, P. (2006). La vida: un relato en busca de narrador. Ágora, 25(2), 9-22.

Ricoeur, P. (2008). Lo justo 2. Madrid: Editorial Trotta.

Rodríguez, E. (2008). Ciencia social performativa: alcances de una alternativa metodológica. Nómadas, (29), 142-155.

Ryfe, D. (2002). The practice of deliberative democracy: a study of 16 deliberative organizations. Political Communication, 19, 359-377.

Ryfe, D. (2006). Narrative and deliberation in small group forums. Journal of Applied Communication Research, 34(1), 72-93.

Theidon, K. (2006). The mask and the mirror: facing up to the past in postwar Perú. Anthropologica, 87-100.

Torres, N. (2016). El camino de la experiencia estética: entre la vivencia y la comprensión. Cuadernos de Filosofía Latinoamericana, 37(2016), 103-115. 
Tornero, A. (2008). El tiempo, la trama y la identidad del personaje a partir de la teoría de Paul Ricoeur. Revista de Humanidades: Tecnológico de Monterrey, (24), 51-79.

Van Manen, M. (1997). Researching Lived Experience. Human Science for an Action Sensitive Pedagogy. London, UK: The Althouse Press.

Zapata, G. (2009). Ética narrativa en Paul Ricœur. Signo y pensamiento, 28(55), 80-91. 